\title{
Left ventricular remodeling and dysfunction in primary aldosteronism
}

\author{
Cheng-Hsuan Tsai $\mathbb{1}^{1,2} \cdot$ Chien-Ting Pan $\mathbb{1}^{2,3} \cdot$ Yi-Yao Chang ${ }^{4} \cdot$ Zheng-Wei Chen ${ }^{2,3} \cdot$ Vin-Cent Wu ${ }^{5} \cdot$ \\ Chi-Sheng Hung ${ }^{2,6} \cdot$ Yen-Hung Lin $\mathbb{1}^{2,6}$
}

Received: 21 February 2020 / Revised: 24 September 2020 / Accepted: 1 October 2020 / Published online: 16 October 2020

(c) The Author(s), under exclusive licence to Springer Nature Limited 2020

\begin{abstract}
Primary aldosteronism (PA) is a common cause of secondary hypertension and is associated with worse cardiovascular outcomes. The elevated aldosterone in PA leads to left ventricular (LV) remodeling and dysfunction. In recent decades, clinical studies have demonstrated worse LV remodeling including increased LV mass and cardiac fibrosis in patients with PA compared to patients with essential hypertension. Several mechanisms may explain the process of aldosterone-induced LV remodeling, including directly profibrotic and hypertrophic effects of aldosterone on myocardium, increased reactive oxygen species and profibrotic molecules, dysregulation of extracellular matrix metabolism, endothelium dysfunction and circulatory macrophages activation. LV remodeling causes LV diastolic and systolic dysfunction, which may consequently lead to clinical complications such as heart failure, atrial fibrillation, ischemic heart disease, and other vascular events. Adequate treatment with adrenalectomy or medical therapy can improve LV remodeling and dysfunction in PA patients. In this review, we discuss the mechanisms of aldosterone-induced LV remodeling and provide an up-to-date review of clinical research about LV remodeling-related heart structural changes, cardiac dysfunction, and their clinical impacts on patients with PA.
\end{abstract}

\section{Introduction}

Primary aldosteronism (PA) is an important cause of secondary hypertension, and its prevalence ranges from 5 to $15 \%$ of hypertension patients [1]. PA is characterized as

Yen-Hung Lin

austinr34@gmail.com

1 Department of Internal Medicine, National Taiwan University Hospital Jinshan Branch, New Taipei City, Taiwan

2 Division of Cardiology, Department of Internal Medicine, National Taiwan University Hospital and National Taiwan University College of Medicine, Taipei, Taiwan

3 Department of Internal Medicine, National Taiwan University Hospital Yun-Lin Branch, Yun-Lin, Taiwan

4 Cardiology Division of Cardiovascular Medical Center, Far Eastern Memorial Hospital, New Taipei City, Taiwan

5 Division of Nephrology, Department of Internal Medicine, National Taiwan University Hospital and National Taiwan University College of Medicine, Taipei, Taiwan

6 Cardiovascular Center, National Taiwan University Hospital, Taipei, Taiwan excessive endogenous aldosterone production from adrenal adenoma or hyperplasia, which is unresponsive to renin regulation. Subsequently, the excess aldosterone can cause more cardiovascular complications, including coronary artery disease, myocardial infarction, stroke, transient ischemic attack, atrial fibrillation and heart failure than in patients with essential hypertension (EH) [2-8]. In addition, it can also lead to cardiovascular remodeling and dysfunction [9-11]. Clinical studies have demonstrated that patients with PA have more left ventricular (LV) remodeling including increased LV mass and cardiac fibrosis than patients with EH [12-17].

LV remodeling in PA includes two parts: LV hypertrophy $(\mathrm{LVH})$ and fibrosis. LV remodeling is the result of the response of cardiomyocytes, non-myocyte resident cells and circulatory cells to cardiac injuries caused by various stimuli, including aldosterone [18]. These molecular, cellular, and interstitial alterations can lead to changes in cardiac size, mass, geometry and function, and then to LV remodeling [19] (Fig. 1). Furthermore, LV remodeling may lead to both LV systolic and diastolic dysfunction, and also to unfavorable outcomes including heart failure, atrial fibrillation, and malignant arrhythmias [20]. 


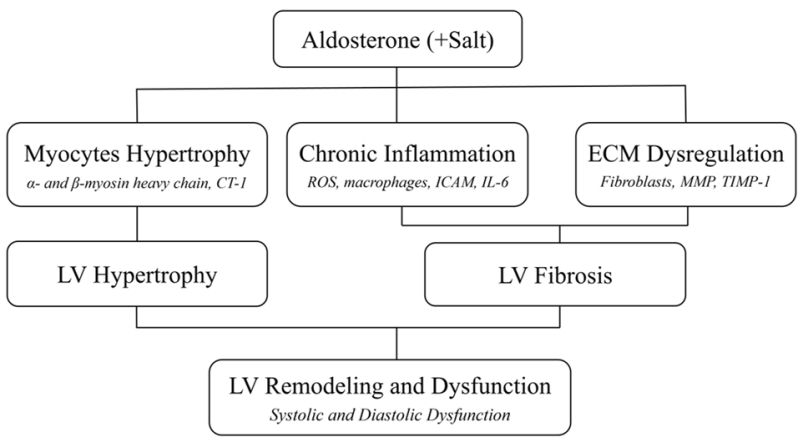

Fig. 1 There are three major mechanisms of alsosterone induced LV remodeling including myocytes hyperthropathy, chronic inflammation and ECM dysregulation. These detrimental effects will induce LV hypertrophy and fibrosis and then cause LV systolic and diastolic dysfunction. The salt will potentiate these effects. CT-1 cardiotrophin-1, ROS reactive oxygen species, ICAM intercellular adhesion molecule, IL-6 interleukin-6, MMP matrix metalloproteinase, TIMP-1 tissue inhibitor of metalloproteinases-1, LV left ventricle.

In this review, we discuss the mechanisms of aldosterone-induced LV remodeling and provide an up-todate review of clinical research about LV remodelingrelated heart structural changes, cardiac dysfunction, and their clinical impacts on patients with PA.

\section{The mechanisms of $L V$ remodeling in $P A$ patients}

$\mathrm{LV}$ remodeling is a process of changes in $\mathrm{LV}$ size, shape, texture, and function regulated by complex interactions between several hemodynamic and non-hemodynamic variables, including neurohormonal activation [21]. Clinical studies have also demonstrated worse LVH and LV fibrosis independently of hemodynamic effects in patients with PA compared to those with EH [14-16], which emphasizes the role of aldosterone in LV remodeling. Animal studies have shown that chronic increases in aldosterone with high salt intake increase $\mathrm{LVH}$ and cardiac fibrosis, which play important roles in LV remodeling [22-24]. Furthermore, Catena et al. demonstrated that urinary sodium excretion was correlated with the degree of LV reverse remodeling after both medical and surgical treatment in PA patients [25]. These studies emphasized that dietary salt intake plays an important role for LV remodeling [26] and even after successful treatment for PA [25].

\section{Mechanisms of aldosterone-induced LV hypertrophy}

Brilla et al. showed that aldosterone could directly stimulate hypertrophy of neonatal rat ventricular cardiomyocytes [27], and that this response was associated with increased
mRNA levels of $\alpha$ - and $\beta$-myosin heavy chain. Furthermore, the authors showed that this response was associated with the activation of mineralocorticoid receptors (MRs), extracellular signal-regulated kinase (ERK), c-Jun N-terminal kinase and protein kinase $\mathrm{C}-\alpha$ [27]. In human vascular smooth muscle cells, Gros et al. showed that aldosterone could mediate myosin light-chain phosphorylation in a dose-dependent manner, and that this was inhibited by an MR antagonist and phosphatidylinositol 3-kinase (PI3K) inhibition [28]. On the other hand, cardiotrophin-1 (CT-1) is a cytokine which can induce the hypertrophy of cardiomyocytes, and has been shown to increase the expression of myosin light chain and skeletal $\alpha$-actin and enhance myosin light chain phosphorylation [29]. The myocardial expression of CT-1 has been shown to be increased in aldosteroneinfusion mice with high salt intake [30]. Moreover, aldosterone has been shown to induce $\mathrm{LVH}$ in wild-type mice, whereas CT-1-null mice have been shown to be resistant to aldosterone-induced LVH and fibrosis [30]. Taken together, these findings support the hypertrophic effects of aldosterone on the myocardium.

\section{Mechanisms of aldosterone-induced LV fibrosis}

Weber et al. first reported the aldosterone can cause cardiac fibrosis in 1991 [31]. Subsequent basic and clinical studies revealed that aldosterone promotes cardiac fibrosis through complex mechanisms involving the activation of MRs and glucocorticoid receptors (GRs) through genomic and nongenomic pathways. The direct effects of aldosterone and its complex intracellular pathways contribute to chronic inflammation, dysregulation of extracellular matrix (ECM) metabolism, and finally cardiac fibrosis.

\section{Aldosterone induces chronic inflammation through reactive oxygen species, pro-inflammatory molecules and macrophages}

Inflammation is an essential step for tissue repair, however chronic inflammation will induce fibrosis. The chronic administration of aldosterone with high salt intake has been shown to induce inflammation and profibrotic responses in the heart, vasculature, and kidneys [24, 32, 33]. The mechanisms involved in this process include the formation of reactive oxygen species (ROS) and increased expressions of profibrotic and pro-inflammatory molecules [34-36].

ROS play an important role in the generation of $\mathrm{LV}$ fibrosis. Aldosterone has been shown to increase nicotinamide adenine dinucleotide phosphate oxidase activity and decrease the expression of glucose-6-phosphate dehydrogenase (G6PD), thereby increasing oxidative stress [34, 35, 37-39]. In addition, aldosterone has been shown to promote inflammation by stimulating the generation of 
ROS, which then activate pro-inflammatory transcription factors such as nuclear factor kappa B [40]. Antioxidants and MR antagonists can attenuate the inflammatory response [34].

Macrophages also play a crucial role in aldosteroneinduced inflammation and fibrosis. Aldosterone with high salt intake has been shown to activate MRs and increase the expression of pro-inflammatory genes in macrophages [41]. In addition, the macrophage-specific MR knockout of the gene encoding MRs has been shown to prevent cardiac fibrosis induced by aldosterone in mice [42]. Aldosterone also can increase the expression of intercellular adhesion molecule on endothelial cells, which can then induce macrophage infiltration and facilitate the inflammatory process [43].

Aldosterone has been shown to stimulate the expression of proinflammatory and profibrotic mediators such as transforming growth factor- $\beta 1$, plasminogen activator inhibitor 1, endothelin 1, connective tissue growth factor, placental growth factor, osteopontin, and galectin-3 [39, 44, 45]. Another pro-inflammatory biomarker, IL-6, has been shown to be elevated in PA patients compared with $\mathrm{EH}$ controls [36]. In addition, our previous study showed that IL-6 plays an important role in aldosterone-induced macrophage recruitment and consequent LV fibrosis $[36,46]$. These pro-inflammatory and profibrotic molecules can cause chronic inflammation and cardiac fibrosis.

\section{Dysregulation of extracellular matrix metabolism}

Fibrosis occurs when collagen and matrix production exceed their degradation by matrix metalloproteinases. Abnormal fibroblast activation with the excess accumulation of ECM protein causes fibrosis. Aldosterone promotes collagen secretion and synthesis from cardiac myocytes and fibroblasts through the activation of MRs, oxidative stress, and chronic inflmmation [47-49]. In addition, aldosterone has also been shown to activate GRs and further inhibit the degradation of collagen, which then leads to cardiac fibrosis [50]. Our previous study demonstrated that tissue inhibitor of metalloproteinases-1 (TIMP-1) protein plays a crucial role in this process [50]. Further studies are needed to understand the role of GRs and their interactions with MRs in cardiac fibrosis.

\section{Role of cortisol excess in LV remodeling in PA patients}

Cortisol excess also contributes to $\mathrm{LVH}$ in PA patients. A recent study revealed that glucocorticoid co-secretion was frequently found in PA and contributes to associated metabolic risk [51]. Interestingly, cortisol has much higher circulating level compared with aldosterone. In tissue with
$11 \beta$-hydroxysteroid dehydrogenase (11 $\beta$-HSD2), the cortisol will be converted to MR-inactive cortisone and therefore aldosterone can active the MRs [52, 53]. However, the expression of $11 \beta$-HSD2 in cardiomyocytes is not abundant and the most MRs in the cardiomyocytes are occupied by cortisol $[52,54]$. This has raised the attention of the effects of cortisol in cardiac remodeling in PA [53]. The effects of cortisol on MRs are bivalent and dynamic. Normally, it occupies the MR as an antagonist. However, when the cells have oxidative stress or damage, the cortisol becomes a MR agonist and works as aldosterone [53, 55]. McQuarrie et al. showed urinary corticosteroid excretion was associated with cardiac remodeling in patients with chronic kidney disease [56]. Adolf et al. demonstrated that elevated total glucocorticoid excretion was correlated with increased LVMI and higher degree of reverse LV remodeling after PA treatment [57]. Mihailidou et al. showed that glucocorticoid could activate the cardiac MRs during experimental myocardial infarction in rat model, which can be blocked by MR antagonist instead of GR antagonist [55]. These studies partially illustrated the role of excess glucocorticoid in PA and LV remodeling. However, further studies are needed.

\section{Left ventricular remodeling in PA- clinical perspective}

\section{LV remodeling in PA patients and clinical tools for evaluation}

LV remodeling in PA patients manifests as changes in LV morphology and structure, including increases in LV mass, wall thickness, and concentric remodeling, and alterations in LV texture, which present as increased LV myocardial fibrosis. The clinical assessment of LV remodeling in patients with PA requires many different diagnostic tools, with a focus on echocardiography due to its noninvasiveness and easy ready-to-use properties, and cardiac magnetic resonance imaging (MRI), an ideal alternative assessment method due to its accuracy and low interoperator variability, with other less commonly used methods such as endomyocardial biopsy. A summary of studies on PA, LV remodeling and related target treatment effects on LV structure in comparison to controls is shown in Table 1.

\section{Clinical studies of PA and treatment effects on LVH}

\section{LVH in PA: clinical studies and treatment effects}

$\mathrm{PA}$ is associated with a higher degree of LVH and increased LV mass index (LVMI) compared to matched $\mathrm{EH}$, and treatment of PA is related to regression of $\mathrm{LVH}$, as shown in 


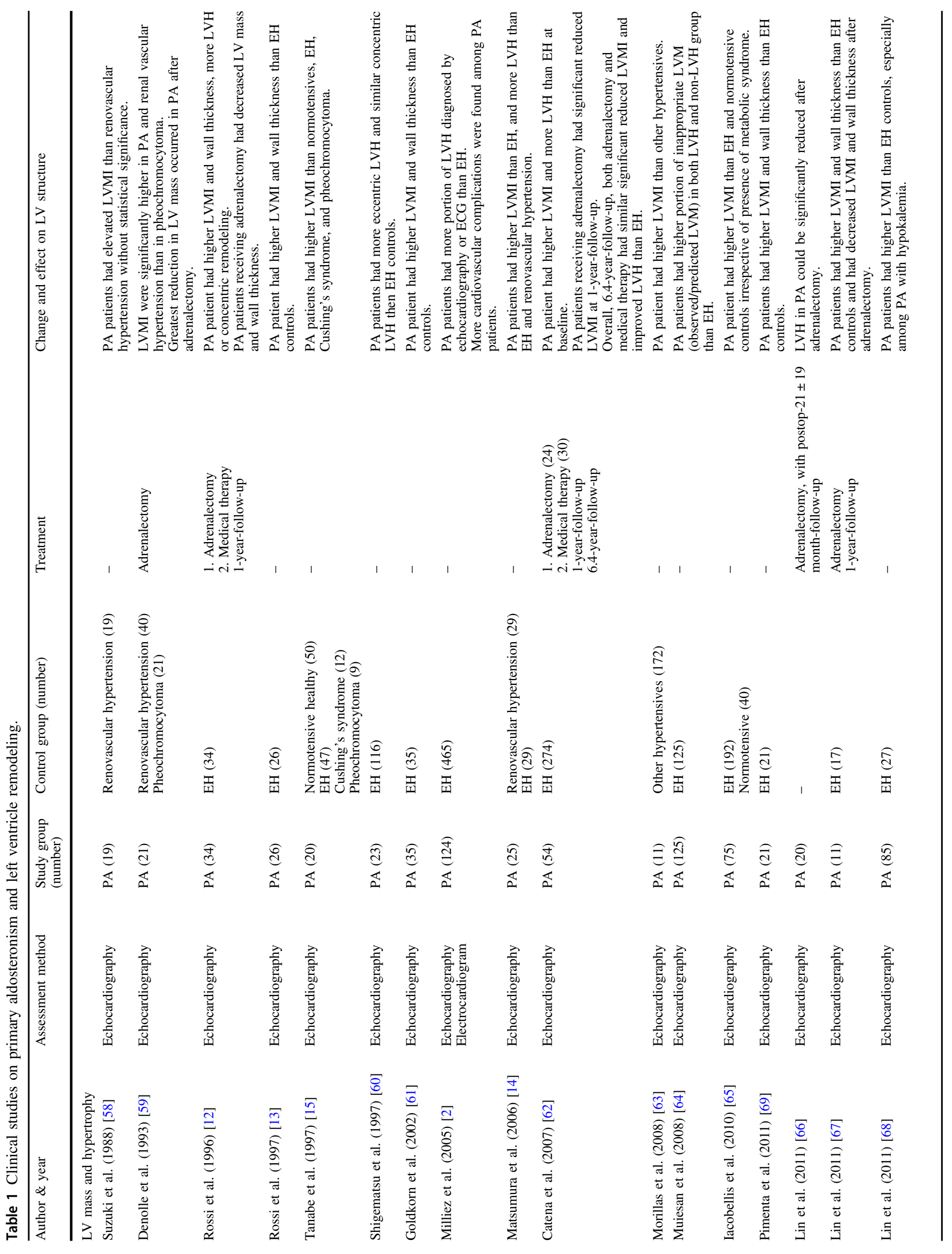




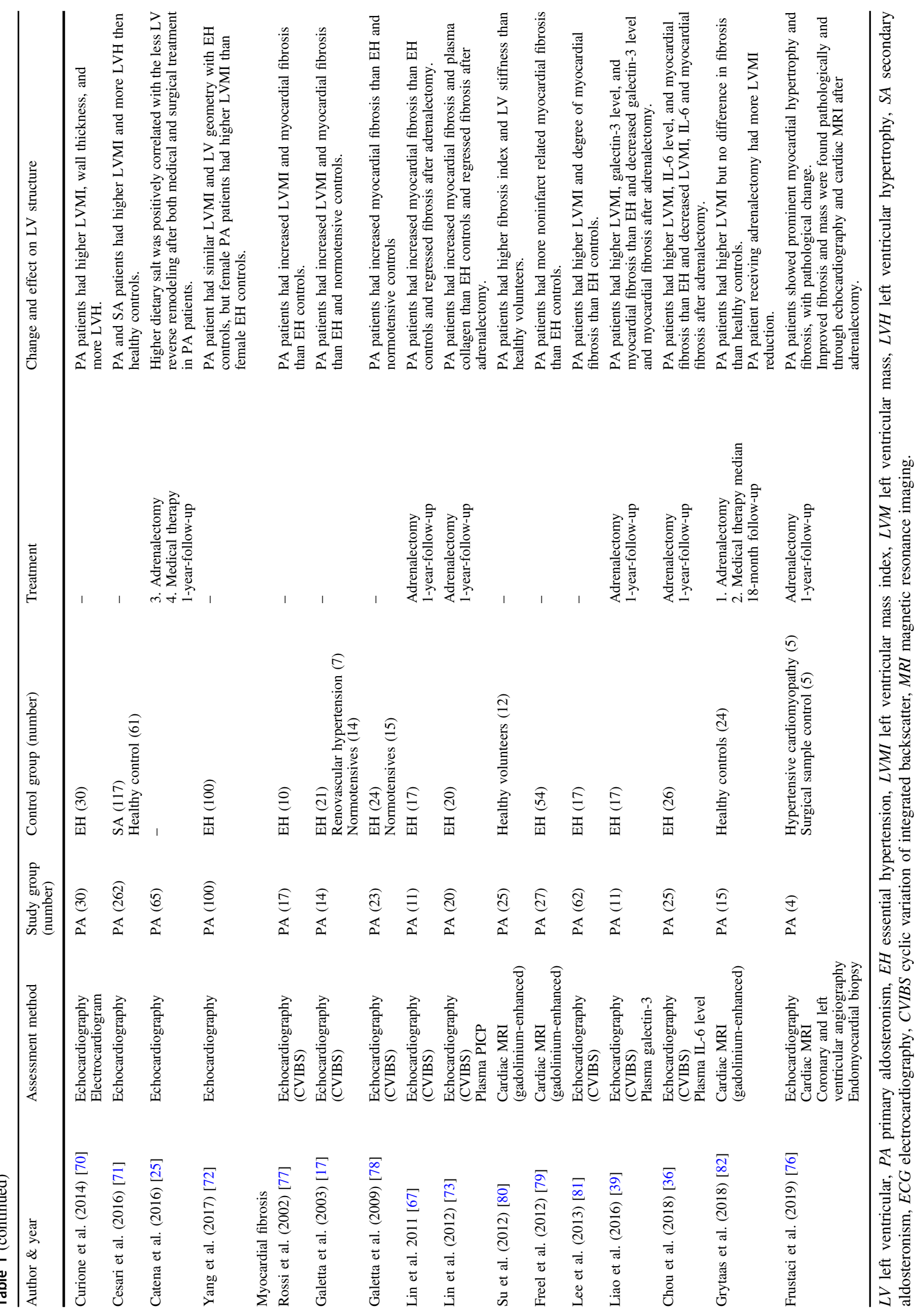


Table 1 [2, 12-15, 58-72]. In 1996, Rossi et al. investigated well-matched PA and EH individuals, and found the significant decreases of LV mass in PA patients who received adrenalectomy [12]. Subsequently, many other studies also reported similar findings [2, 13-15, 60-73]. A higher degree and percentage of LVH has also been linked to increased cardiovascular adverse events in PA patients compared with EH controls [2]. In the long-term, treatment of PA with surgical adrenalectomy and medical MR antagonist therapy have both been reported to decrease LVMI and regress LVH, with more rapid and obvious effects with adrenalectomy [62]. Adrenalectomy has been widely studied and been shown to significantly reduce LV mass and effectively reverse LVH among PA patients compared with EH controls [12, 62, 66, 68].

\section{Factors affecting LV mass and LV mass regression in PA}

Among PA patients, LVMI has been correlated with blood pressure [12], serum potassium level [68], estimated glomerular filtration rate [74], and urine sodium levels [75]. Changes in systolic blood pressure (SBP), postoperative SBP, pre-operative LVMI, and postoperative potassium have been correlated with changes in LVMI [66, 68]. PA has also been associated with LVH independently of the effect from blood pressure. In 2008, Muiessan et al. further investigated inappropriate $\mathrm{LV}$ mass derived from the ratio of measured LVMI and predicted LVMI estimated using body size and blood pressure, and found that PA patients had a higher ratio of inappropriate LV mass than EH controls regardless of the presence of a diagnosis of LVH [64]. An increased ratio of inappropriate LV mass represents the pathogenesis of LVH beyond physiological compensation of hypertension, which is associated with endocrinological differences between PA patients and EH controls.

\section{Clinical studies of PA and treatment effects on myocardial fibrosis}

Myocardial biopsy is the gold standard for studies of myocardial fibrosis; however, it is limited by its invasiveness. One recent study from Italy reported pathological findings from endomyocardial biopsies in PA patients, and revealed prominent myocardial hypertrophy and fibrosis, with reversible water accumulation in the cytosol and organelles of cardiomyocytes and microvascular smooth muscle cells after adrenalectomy [76]. However, the small sample size limited the clinical and statistical power with regards to proving an increase in myocardial fibrosis due to PA. Clinically, myocardial fibrosis in PA is mostly evaluated by echocardiography and cardiac MRI, in conjunction with serum biomarkers that are elevated during increased myocardial fibrosis, as listed in Table 1 [17, 36, 39, 67, 73, 76-82].

\section{Myocardial fibrosis in PA: echocardiography}

Collagen content in the myocardium in an important determinant of integrated backscatter in echocardiography [83]. Recently, ultrasonic tissue characterization by cyclic variation of integrated backscatter (CVIBS) has been used as a non-invasive tool to assess myocardial fibrosis in hypertensive patients [83]. In 2002, Rossi et al. was the first to use echocardiography to evaluate myocardial fibrosis in PA patients, and reported lower CVIBS signals in PA patients compared with EH controls [77]. Our previous study also showed that PA patients had lower CVIBS and higher plasma carboxy-terminal propeptide of procollagen type I (PICP, a fibrosis marker) compared to EH patients [67]. In addition, we showed the reversal of CVIBS and plasma PICP levels after adrenalectomy [67].

\section{Myocardial fibrosis in PA: cardiac MRI}

Myocardial fibrosis in PA also can be assessed by cardiac MRI with gadolinium-enhanced imaging or other imaging processing methods evaluating the texture of the myocardium. PA patients have been shown to have a higher fibrosis index, LV stiffness, and noninfarct-related fibrosis compared with healthy volunteers or EH controls, while only one small-sized study has reported conflicting data [82]. Although no difference was found in myocardial fibrosis after treatment in that study [82], it was limited by a small sample size.

\section{LV dysfunction in PA patients}

\section{LV diastolic dysfunction in PA}

PA patients have been shown to have more severe diastolic dysfunction than EH patients [78, 84]. To evaluate diastolic dysfunction, Doppler echocardiography, tissue Doppler imaging (TDI) and MRI are commonly used in current clinical practice. Studies of diastolic dysfunction and related target treatment effects in PA patients are summarized in Tables 2 and 3.

\section{Diastolic function evaluation in PA: Doppler echocardiography}

In animal models, rats subjected to aldosterone infusion and salt intake [85] and transgenic (mRen2) 27 rats with an excess serum aldosterone level [86] have been shown to have impaired LV diastolic function by Doppler echocardiography and MRI. The effect of aldosterone on diastolic function in PA patients was first proposed by Rossi et al. in 1996 [12] via measuring E/A integral ratio and atrial 


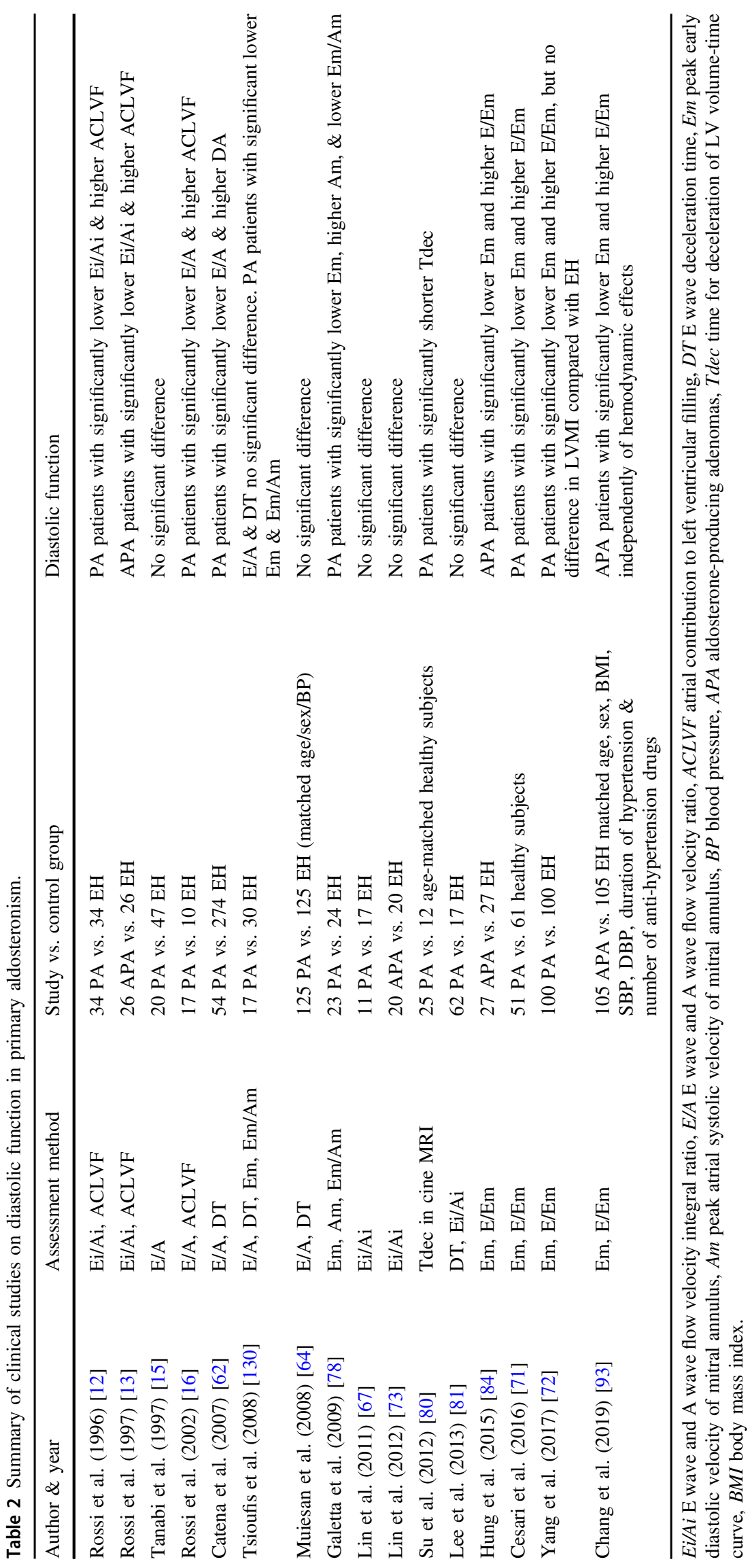


contribution to LV filling. However, these parameters are influenced by preload [87] and result in inconsistent interpretations. Our previous study showed no significant difference in E/A integral ratio between PA and EH patients [73]. A more reliable parameter to evaluate diastolic function is necessary.

Diastolic function evaluation in PA: tissue Doppler imaging

A newer parameter obtained via TDI is E/Em (Em, peak early diastolic velocity of mitral annulus), which has been shown to be less preload-dependent [88, 89] and more correlated with LV diastolic pressure than any other echocardiographic parameter [90]. Some studies have used TDI to investigate diastolic function in PA patients, however they have included a small sample size, used healthy people as the control group, or reported contrasting LVMI results compared with previous studies [71, 72, 91]. In addition, in these studies, the baseline blood pressure, antihypertensive medications, and age were significantly different between the two study groups. However, the severity of diastolic dysfunction is proportional to blood pressure [92]. In our recent study [93], we used propensity score matching analysis to mitigate the effect of blood pressure on diastolic function between aldosterone-producing adenomas (APA) and EH patients. There were 105 patients in each group after matching, and the APA patients had significantly worse diastolic function than the EH patients, as reflected by a lower Em and higher E/Em. This indicated that the effect of aldosterone on diastolic dysfunction was independent of hemodynamic change.

\section{Diastolic function evaluation in PA: cardiac MRI}

Cardiac MRI is a standard tool to evaluate LV function via LV volume qualification, and the time for deceleration (Tdec) can be determined by LV volume-time curve as an indicator of LV stiffness [94]. In our previous study [80], 25 patients with PA and 12 age-matched healthy volunteers underwent cardiac MRI, which showed that the patients with PA had a significantly shorter Tdec, indicating that they had impaired diastolic function.

\section{Treatment effect on diastolic function in patients with PA: MR antagonist and adrenalectomy}

A previous animal study [86] investigated the effect of an MR antagonist on diastolic function using transgenic (mRen2) 27 rats, which had high blood pressure, elevated plasma aldosterone levels, and evidence of cardiac hypertrophy, fibrosis and diastolic dysfunction as evaluated by MRI. The rats were treated with high and low doses of spironolactone for 3 weeks, which resulted in the reversal of 
ventricular hypertrophy, fibrosis, and diastolic function independently of changes in blood pressure. In a clinical study including 31 patients with PA, 15 of the patients with confirmed APA underwent adrenalectomy and the remaining 16 patients took spironolactone for 1 year. The results revealed improved diastolic function in both groups, as evidenced by a decrease in E/Em [95].

For patients with APA, although adrenalectomy can improve blood pressure control and reverse LVM $[12,16,62,96]$ and myocardial fibrosis [67, 73], the reversibility of diastolic dysfunction is still under debate [62, 91, 97, 98]. In a previous study of adrenalectomy among 110 PA patients, diastolic function as assessed by prolongation of deceleration time (DT) significantly improved, but there was no significant change in atrial contribution to LV filling [97]. In another study of 24 PA patients who underwent adrenalectomy, diastolic function as assessed by E/A ratio and DT improved, but without statistical significance [62]. In our recent study [93], diastolic function improved after adrenalectomy in the APA patients as evidenced by a significant increase in Em and significant decrease in $\mathrm{E} / \mathrm{Em}$ ratio. The improvement in diastolic function after adrenalectomy was associated with baseline E/Em and changes in LVMI after adrenalectomy.

\section{LV systolic dysfunction in PA}

Compared with studies of LV diastolic dysfunction, relatively few studies have investigated LV systolic dysfunction in PA. In the evaluation of systolic function, endocardial measurements including LV ejection fraction (LVEF) and endocardial fractional shortening (eFS), midwall fractional shortening (mFS), TDI and strain echocardiography are commonly used. Studies on systolic function measurement in PA patients and treatment effect are summarized in Table 4.

\section{Systolic function evaluation in PA: endocardial measurements}

Most previous studies on systolic function as measured by echocardiography have used endocardial parameters such as LVEF or eFS and shown no difference between patients with PA and EH [13-15, 61, 62, 64, 65, 68, 72, 77, 84, 99101]. Gaddam et al. also demonstrated that LVEF measured by MRI was similar between patients with hyperaldosteronism and resistant hypertension with normal aldosterone levels [102].

\section{Systolic function evaluation in PA: midwall measurements}

With regards to LV mFS, most studies have demonstrated no difference between PA and EH patients [17, 61, 62, 99].
Only one study demonstrated that $\mathrm{mFS}$ was lower in PA patients compared with EH patients, and further subgroup analysis showed that the impairment in $\mathrm{mFS}$ was more pronounced in PA patients with inappropriate LV mass [64].

\section{Systolic function evaluation in PA: tissue Doppler echocardiography}

In TDI, mitral annular systolic velocity can also be used to detect the early signs of LV systolic dysfunction [103]. Galetta et al. found that PA patients had a lower mitral annular systolic velocity ( $\mathrm{Sm}$ ) (at interventricular septum and lateral wall levels) compared with EH patients and normotensive healthy controls [78]. However, Choi et al. found that baseline Sm was not different between patients with higher and lower plasma aldosterone-to-renin ratio (ARR) with a cut-off level of 30 [104]. Furthermore, they found that exertional $\mathrm{Sm}$ was lower in the patients with a higher ARR at 50-watts and peak exercise [104]. In subgroup analysis, Hidaka et al. found that $\mathrm{Sm}$ showed no difference between patients with APA and idiopathic hyperaldosteronism [105].

\section{Systolic function evaluation in PA: strain echocardiography}

However, conventional measurements such as LVEF, eFS, and $\mathrm{mFS}$ have limitations in assessing LV systolic performance in hypertensive patients and patients with LVH [106, 107]. Recently, speckle tracking echocardiography has been used for quantitative assessments of LV systolic performance by myocardial deformation, and it has been shown to be a more sensitive tool to detect systolic dysfunction [108]. Among parameters of myocardial deformation, longitudinal strain is considered to be the most useful due to its clinical significance in patients with structural remodeling in hypertensive heart disease [109].

In 2016, Cesari et al. reported a lower peak systolic septal strain in PA patients than in patients without hypertension, including normal healthy controls and patients with secondary aldosteronism, in whom hyperaldosteronism was due to a physiological response to reduced intravascular volume or sodium status [71]. However, whether this LV dysfunction was caused by an excess of aldosterone or merely the effect of blood pressure was unclear [71]. In our previous study, we found that PA patients had a lower magnitude of global longitudinal strain compared to $\mathrm{EH}$ patients with comparable blood pressure, which indicated subclinical systolic dysfunction in PA patients [9]. This finding suggested that the effect of aldosterone on systolic function impairment was independent of hemodynamics. Boulestreau et al. also reported similar results that were compatible with our study [110]. In addition, Wang et al. 


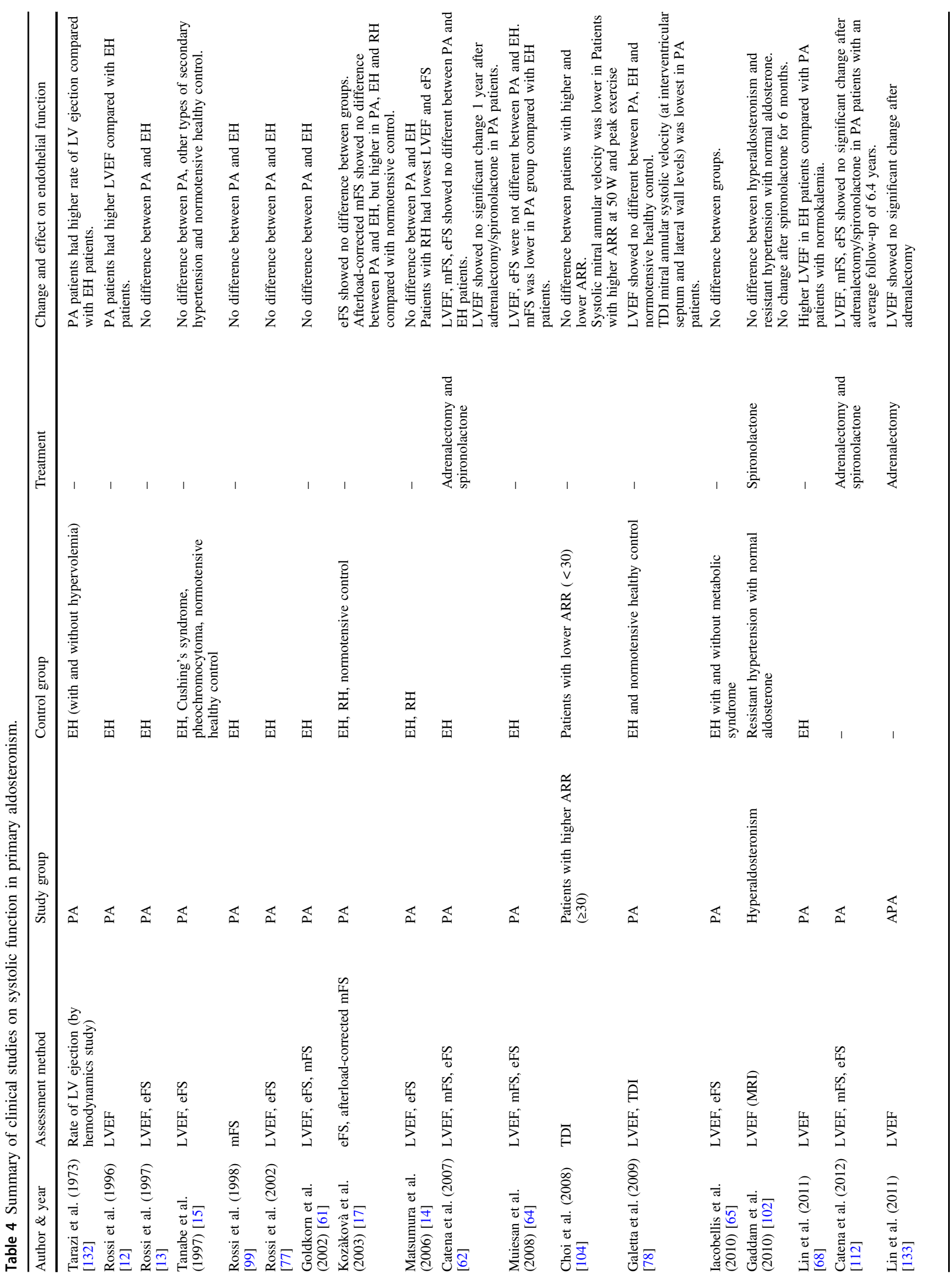




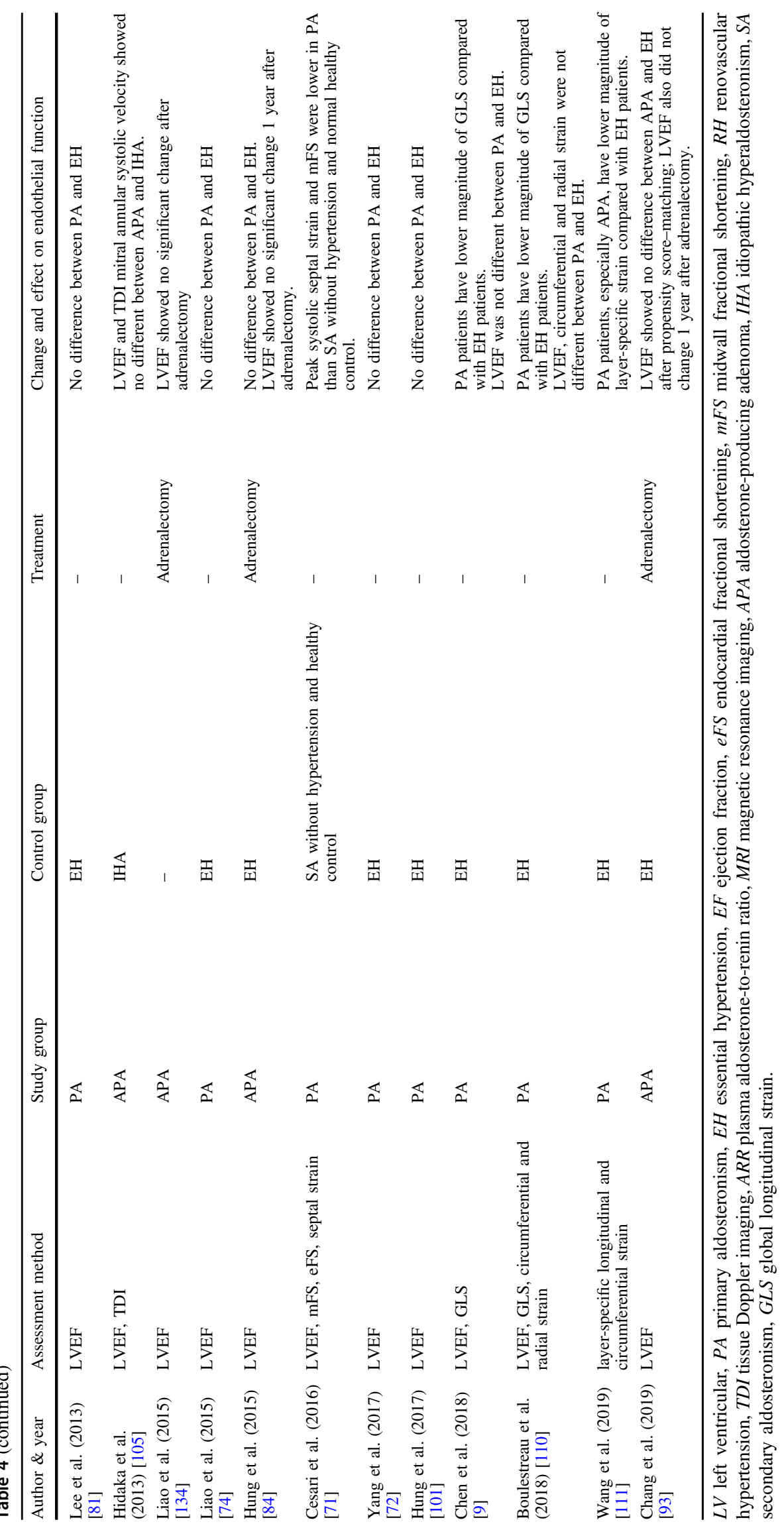


demonstrated that PA patients (and especially APA patients) had more impaired regional systolic function, as measured by layer-specific strain echocardiography, compared with EH patients [111].

\section{Treatment effect on systolic function in patients with PA: MR antagonist and adrenalectomy}

With regards to the treatment effect of PA on cardiac function, although both adrenalectomy and spironolactone have been shown to be effective in reducing LV mass, no significant changes in LVEF, eFS, or mFS have been shown after treatment $[62,84,91,93,112,113]$. To date, no strain study has assessed the effect of treatment in PA patients.

\section{Clinical consequence of $\mathrm{LV}$ remodeling}

The process of LV remodeling involves LV fibrosis and hypertrophy [61, 72]. These morphological changes will further influence diastolic and systolic function to different extents, causing subtle to overt cardiac failure. Prolonged isovolumic LV relaxation, slower LV filling, and increased diastolic LV stiffness contribute to increased LV wall stress and the elevation of LV end diastolic pressure (LVEDP), which are the central pathophysiological mechanisms of heart failure with preserved ejection fraction [114]. If the changes in cardiac structure become more serious in a vicious cycle, this may further influence LV systolic performance and even lead to heart failure with reduced ejection fraction [115]. Clinically, Savard et al. reported an increased prevalence of heart failure in PA patients compared with EH patients (4.1\% vs. 1.2\%) [5]. In addition, a recent meta-analysis by Monticone et al. also showed a twofold increased risk of heart failure in PA patients compared to EH patients [7].

Moreover, LV remodeling with subclinical systolic dysfunction and diastolic dysfunction, which further enlarge the left atrium due to an elevated LVEDP, may be a crucial determinant for increased arrhythmia. Dilatation of the left atrium and increased volume have been correlated with the pathogenesis of atrial fibrillation [116]. In addition, atrial fibrosis, myocyte hypertrophy, and conduction disturbances due to an excess of aldosterone have been shown to contribute to a pro-arrhythmogenic effect [117]. A previous study by Yang et al. reported a higher left atrium volume index in PA patients compared with EH controls [72]. Wang et al. also demonstrated lower left atrial velocity, strain and strain rate, and higher left atrial stiffness index in PA patients than in EH controls [118]. From a clinical aspect, emerging evidence has shown increased atrial fibrillation in PA patients compared with $\mathrm{EH}$ patients $[2,3,5,6,97,119]$. According to the recent meta-analysis by Monticone et al., the odds ratio of atrial fibrillation in PA to EH patients was 3.52 [7]. In our recent study regarding APA patients using a health insurance database, the APA patients who underwent adrenalectomy had a lower risk of new-onset heart failure compared to EH patients [120]. In contrast, the incidence was comparable between APA patients who received medical treatment and EH patients [120].

Moreover, LV mass has been reported to increase in parallel with the progression of atherosclerosis, and this has been independently related to the risk of subsequent cardiovascular morbidity, including stroke and myocardial infarction [121, 122]. LV hypertrophy-induced myocardial dysfunction and ischemia has also been associated with the occurrence of arrhythmia and heart failure [123]. In addition to LV remodeling, aldosterone can cause vascular tone dysfunction, vascular inflammation, atherosclerosis, and vascular remodeling [124]. This damage caused by an excess of aldosterone affects both cardiovascular and cerebrovascular systems. Murata et al. showed that the increases in cardiovascular and cerebrovascular risks in patients with PA were related to plasma aldosterone level [125]. Many studies have demonstrated a higher rate of cardiocerebrovascular complications, including coronary artery disease, nonfatal myocardial infarction, stroke and transient ischemic attack in PA patients than in EH controls [2, 3, 5$7,119,126]$. Our recent study also demonstrated similar finding that PA patients who received adrenalectomy had a comparable incidence of stroke compared to patients with EH [127]. In contrast, the incidence was significantly higher in PA patients who received medical treatment with an MR antagonist compare to EH patients [127]. However, sufficient MR blockage by MR antagonist also mitigates cardiovascular risk in PA patients. Hundemer et al. demonstrated that PA patients treated with MR antagonist had significantly higher risk of cardiovascular events and mortality compared with EH patients. The excess risk was limited to PA patients whose renin activity remained suppressed $(<1$ $\mu \mathrm{g} / \mathrm{L}$ per $\mathrm{h}$ ) under MR antagonist treatment. In contrast, PA patients who had unsuppressed renin ( $\geq 1 \mu \mathrm{g} / \mathrm{L}$ per $\mathrm{h}$ ) under MR antagonist treatment had no significant excess risk [128]. Similarly, medically treated PA patients with suppressed renin activity (insufficient MR blockade) had high risk of atrial fibrillation compared with age-matched $\mathrm{EH}$ patients. However, there was no associated risk in medically treated PA patients with sufficient MR blockage and surgically treated PA patients [129].

LV remodeling in PA patients can cause the subsequent progression of heart failure, atrial fibrillation, ischemic heart disease, and cerebrovascular accidents, which are associated with worse clinical outcomes. LV hypertrophy has also been identified as an independent risk factor for cardiovascular morbidity and mortality [122]. In addition, 
myocardial fibrosis has been adversely associated with clinical outcomes [20]. All these studies emphasize the importance and clinical impact of LV remodeling resulting from hypertrophy and fibrosis in PA patients.

\section{Conclusion}

Aldosterone stimulates LV remodeling via cardiac fibrosis and hypertrophy in patients with PA. The production of ROS, inflammation, profibrotic mediators, collagen formation, myosin generation, and phosphorylation induced by excess aldosterone contribute to LV remodeling. The structural changes after LV remodeling are associated with worse diastolic and systolic function and are associated with worse clinical outcomes.

Acknowledgements This research was supported by grants from the Ministry of Science and Technology (MOST 105-2314-B-002-122MY3, MOST 106-2314-B-002-169-MY3 and MOST 107-2314-B-002 -264 -MY3), National Taiwan University Hospital (NTUH 107-A141, 108-A141, 109-A141, 108-N01, 108-S4382, UN108-37), and the Excellent Translational Medicine Research Projects of National Taiwan University College of Medicine, and National Taiwan University Hospital (109C 101-43).

\section{Compliance with ethical standards}

Conflict of interest The authors declare that they have no conflict of interest.

Publisher's note Springer Nature remains neutral with regard to jurisdictional claims in published maps and institutional affiliations.

\section{References}

1. Rossi GP. Prevalence and diagnosis of primary aldosteronism. Curr Hypertens Rep. 2010;12:342-8.

2. Milliez P, Girerd X, Plouin PF, Blacher J, Safar ME, Mourad JJ. Evidence for an increased rate of cardiovascular events in patients with primary aldosteronism. J Am Coll Cardiol. 2005; 45:1243-8.

3. Catena C, Colussi G, Nadalini E, Chiuch A, Baroselli S, Lapenna $\mathrm{R}$, et al. Cardiovascular outcomes in patients with primary aldosteronism after treatment. Arch Intern Med. 2008;168:80-5.

4. Reincke M, Fischer E, Gerum S, Merkle K, Schulz S, Pallauf A, et al. Observational study mortality in treated primary aldosteronism: the German Conn's registry. Hypertension (Dallas, Tex: 1979). 2012;60:618-24.

5. Savard S, Amar L, Plouin PF, Steichen O. Cardiovascular complications associated with primary aldosteronism: a controlled cross-sectional study. Hypertension (Dallas, Tex: 1979). 2013;62:331-6.

6. Mulatero P, Monticone S, Bertello C, Viola A, Tizzani D, Iannaccone A, et al. Long-term cardio- and cerebrovascular events in patients with primary aldosteronism. J Clin Endocrinol Metab. 2013;98:4826-33.

7. Monticone S, D’Ascenzo F, Moretti C, Williams TA, Veglio F, Gaita F, et al. Cardiovascular events and target organ damage in primary aldosteronism compared with essential hypertension: a systematic review and meta-analysis. The lancet. Lancet Diabet Endocrinol. 2018;6:41-50.

8. Wu VC, Wang SM, Chang CH, Hu YH, Lin LY, Lin YH, et al. Long term outcome of Aldosteronism after target treatments. Sci Rep. 2016;6:32103.

9. Chen ZW, Huang KC, Lee JK, Lin LC, Chen CW, Chang YY, et al. Aldosterone induces left ventricular subclinical systolic dysfunction: a strain imaging study. J Hypertens. 2018;36:353-60.

10. Lin Y-H, Lin L-Y, Chen A, Wu X-M, Lee J-K, Su T-C, et al. Adrenalectomy improves increased carotid intima-media thickness and arterial stiffness in patients with aldosterone producing adenoma. Atherosclerosis. 2012;221:154-9.

11. Liao CW, Lin LY, Hung CS, Lin YT, Chang YY, Wang SM, et al. Time course and factors predicting arterial stiffness reversal in patients with aldosterone-producing adenoma after adrenalectomy: prospective study of 102 patients. Sci Rep. 2016;6:20862.

12. Rossi GP, Sacchetto A, Visentin P, Canali C, Graniero GR, Palatini $\mathrm{P}$, et al. Changes in left ventricular anatomy and function in hypertension and primary aldosteronism. Hypertension. 1996;27:1039-45.

13. Rossi GP, Sacchetto A, Pavan E, Palatini P, Graniero GR, Canali $\mathrm{C}$, et al. Remodeling of the left ventricle in primary aldosteronism due to Conn's adenoma. Circulation. 1997;95:1471-8.

14. Matsumura K, Fujii K, Oniki H, Oka M, Iida M. Role of aldosterone in left ventricular hypertrophy in hypertension. Am J Hypertens. 2006;19:13-8.

15. Tanabe A, Naruse M, Naruse K, Hase M, Yoshimoto T, Tanaka $\mathrm{M}$, et al. Left ventricular hypertrophy is more prominent in patients with primary aldosteronism than in patients with other types of secondary hypertension. Hypertension Res. 1997;20:85-90.

16. Rossi GP, Di Bello V, Ganzaroli C, Sacchetto A, Cesari M, Bertini A, et al. Excess ldosterone Is Associated with Alterations of Myocardial Texture in Primary Aldosteronism. Hypertension. 2002;40:23-27.

17. Kozakova M, Buralli S, Palombo C, Bernini G, Moretti A, Favilla S, et al. Myocardial ultrasonic backscatter in hypertension: relation to aldosterone and endothelin. Hypertension (Dallas, Tex: 1979). 2003;41:230-6.

18. Cohn JN, Ferrari R, Sharpe N. Cardiac remodeling-concepts and clinical implications: a consensus paper from an international forum on cardiac remodeling. Behalf of an International Forum on Cardiac Remodeling. J Am Coll Cardiol. 2000;35:569-82.

19. Azevedo PS, Polegato BF, Minicucci MF, Paiva SA, Zornoff LA. Cardiac remodeling: concepts, clinical impact, pathophysiological mechanisms and pharmacologic treatment. Arquivos Brasileiros de Cardiologia. 2016;106:62-9.

20. González A, Ravassa S, López B, Moreno MU, Beaumont J, José GS, et al. Myocardial Remodeling in Hypertension. Hypertension (Dallas, Tex: 1979). 2018;72:549-58.

21. Sutton MG, Sharpe N. Left ventricular remodeling after myocardial infarction: pathophysiology and therapy. Circulation. 2000;101:2981-8.

22. Brilla CG, Pick R, Tan LB, Janicki JS, Weber KT. Remodeling of the rat right and left ventricles in experimental hypertension. Circulation Res. 1990;67:1355-64.

23. Brilla CG, Weber KT. Reactive and reparative myocardial fibrosis in arterial hypertension in the rat. Cardiovasc Res. 1992;26:671-7.

24. Brilla CG, Weber KT. Mineralocorticoid excess, dietary sodium, and myocardial fibrosis. J Lab Clin Med. 1992;120:893-901.

25. Catena C, Colussi G, Novello M, Verheyen ND, Bertin N, Pilz S, et al. Dietary salt intake is a determinant of cardiac changes after 
treatment of primary aldosteronism: a prospective study. Hypertension. 2016;68:204-12.

26. Pimenta E, Gordon RD, Stowasser M. Salt, aldosterone and hypertension. J Hum Hypertens. 2013;27:1-6.

27. Okoshi MP, Yan X, Okoshi K, Nakayama M, Schuldt AJ, O'Connell TD, et al. Aldosterone directly stimulates cardiac myocyte hypertrophy. J Card Fail. 2004;10:511-8.

28. Gros R, Ding Q, Armstrong S, O'Neil C, Pickering JG, Feldman RD. Rapid effects of aldosterone on clonal human vascular smooth muscle cells. Am J Physiol Cell Physiol. 2007;292: C788-94.

29. Lopez N, Diez J, Fortuno MA. Differential hypertrophic effects of cardiotrophin-1 on adult cardiomyocytes from normotensive and spontaneously hypertensive rats. J Mol Cell Cardiol. 2006;41: 902-13.

30. Lopez-Andres N, Martin-Fernandez B, Rossignol P, Zannad F, Lahera V, Fortuno MA, et al. A role for cardiotrophin-1 in myocardial remodeling induced by aldosterone. Am J Physiol Heart Circ Physiol. 2011;301:H2372-82.

31. Weber KT, Brilla CG. Pathological hypertrophy and cardiac interstitium. Fibros Renin-Angiotensin-Aldosterone Syst Circ. 1991;83:1849-65.

32. Lacolley P, Labat C, Pujol A, Delcayre C, Benetos A, Safar M. Increased carotid wall elastic modulus and fibronectin in aldosterone-salt-treated rats: effects of eplerenone. Circulation. 2002;106:2848-53.

33. Greene EL, Kren S, Hostetter TH. Role of aldosterone in the remnant kidney model in the rat. J Clin Investig. 1996;98: 1063-8.

34. Sun Y, Zhang J, Lu L, Chen SS, Quinn MT, Weber KT. Aldosterone-induced inflammation in the rat heart: role of oxidative stress. Am J Pathol. 2002;161:1773-81.

35. Park YM, Park MY, Suh YL, Park JB. NAD(P)H oxidase inhibitor prevents blood pressure elevation and cardiovascular hypertrophy in aldosterone-infused rats. Biochem Biophys Res Commun. 2004;313:812-7.

36. Chou CH, Hung CS, Liao CW, Wei LH, Chen CW, Shun CT, et al. IL-6 trans-signalling contributes to aldosterone-induced cardiac fibrosis. Cardiovasc Res. 2018;114:690-702.

37. Brown NJ. Aldosterone and vascular inflammation. Hypertension. 2008;51:161-7.

38. Leopold JA, Dam A, Maron BA, Scribner AW, Liao R, Handy $\mathrm{DE}$, et al. Aldosterone impairs vascular reactivity by decreasing glucose-6-phosphate dehydrogenase activity. Nat Med. 2007;13:189-97.

39. Liao CW, Lin YT, Wu XM, Chang YY, Hung CS, Wu VC, et al. The relation among aldosterone, galectin-3, and myocardial fibrosis: a prospective clinical pilot follow-up study. J Investig Med. 2016;64:1109-13.

40. Fiebeler A, Schmidt F, Muller DN, Park JK, Dechend R, Bieringer $\mathrm{M}$, et al. Mineralocorticoid receptor affects AP-1 and nuclear factor-kappab activation in angiotensin II-induced cardiac injury. Hypertension. 2001;37:787-93.

41. Lother A, Berger S, Gilsbach R, Rosner S, Ecke A, Barreto F, et al. Ablation of mineralocorticoid receptors in myocytes but not in fibroblasts preserves cardiac function. Hypertension. 2011;57:746-54.

42. Bienvenu LA, Morgan J, Rickard AJ, Tesch GH, Cranston GA, Fletcher EK, et al. Macrophage mineralocorticoid receptor signaling plays a key role in aldosterone-independent cardiac fibrosis. Endocrinology. 2012;153:3416-25.

43. Caprio M, Newfell BG, la Sala A, Baur W, Fabbri A, Rosano G, et al. Functional mineralocorticoid receptors in human vascular endothelial cells regulate intercellular adhesion molecule-1 expression and promote leukocyte adhesion. Circ Res. 2008;102: 1359-67.
44. Brown NJ. Contribution of aldosterone to cardiovascular and renal inflammation and fibrosis. Nat Rev Nephrol. 2013;9: 459-69.

45. Calvier L, Miana M, Reboul P, Cachofeiro V, Martinez-Martinez E, de Boer RA, et al. Galectin-3 mediates aldosterone-induced vascular fibrosis. Arterioscler Thromb Vasc Biol. 2013;33:67-75.

46. Liao CW, Chou CH, Wu XM, Chen ZW, Chen YH, Chang YY, et al. Interleukin-6 plays a critical role in aldosterone-induced macrophage recruitment and infiltration in the myocardium. Biochim Biophys Acta Mol Basis Dis. 2020;1866:165627.

47. Brilla CG, Zhou G, Matsubara L, Weber KT. Collagen metabolism in cultured adult rat cardiac fibroblasts: response to angiotensin II and aldosterone. J Mol Cell Cardiol. 1994;26: 809-20.

48. Somanna NK, Yariswamy M, Garagliano JM, Siebenlist U, Mummidi S, Valente AJ, et al. Aldosterone-induced cardiomyocyte growth, and fibroblast migration and proliferation are mediated by TRAF3IP2. Cell Signal. 2015;27:1928-38.

49. Rude MK, Duhaney TA, Kuster GM, Judge S, Heo J, Colucci WS, et al. Aldosterone stimulates matrix metalloproteinases and reactive oxygen species in adult rat ventricular cardiomyocytes. Hypertension. 2005;46:555-61.

50. Hung CS, Chou CH, Liao CW, Lin YT, Wu XM, Chang YY, et al. Aldosterone induces tissue inhibitor of Metalloproteinases1 expression and further contributes to collagen accumulation: from clinical to bench studies. Hypertension. 2016;67:1309-20.

51. Arlt W, Lang K, Sitch AJ, Dietz AS, Rhayem Y, Bancos I, et al. Steroid metabolome analysis reveals prevalent glucocorticoid excess in primary aldosteronism. JCI Insight. 2017;2:e93136.

52. van Uum SH, Hermus AR, Smits $P$, Thien T, Lenders JW. The role of 11ß-hydroxysteroid dehydrogenase in the pathogenesis of hypertension. Cardiovasc Res. 1998;38:16-24.

53. Funder JW. Aldosterone and mineralocorticoid receptorsphysiology and pathophysiology. Int J Mol Sci. 2017;18:1032.

54. Slight S, Ganjam VK, Weber KT. Species diversity of $11 \beta-$ hydroxysteroid dehydrogenase in the cardiovascular system. J Lab Clin Med. 1994;124:821-6.

55. Mihailidou AS, Loan LeTY, Mardini M, Funder JW. Glucocorticoids activate cardiac mineralocorticoid receptors during experimental myocardial infarction. Hypertension. 2009;54: 1306-12.

56. McQUARRIE EP, Freel EM, Mark PB, Fraser R, Patel RK, Dargie HG, et al. Urinary corticosteroid excretion predicts left ventricular mass and proteinuria in chronic kidney disease. Clin Sci. 2012;123:285-94.

57. Adolf C, Kohler A, Franke A, Lang K, Riester A, Low A, et al. Cortisol Excess in Patients With Primary Aldosteronism Impacts Left Ventricular Hypertrophy. J Clin Endocrinol Metab. 2018;103:4543-52.

58. Suzuki T, Abe H, Nagata S, Saitoh F, Iwata S, Ashizawa A, et al. Left ventricular structural characteristics in unilateral renovascular hypertension and primary aldosteronism. Am J Cardiol. 1988;62:1224-7.

59. Denolle T, Chatellier G, Julien J, Battaglia C, Luo P, Plouin PF. Left ventricular mass and geometry before and after etiologic treatment in renovascular hypertension, aldosterone-producing adenoma, and pheochromocytoma. Am J Hypertens. 1993;6: 907-13.

60. Shigematsu Y, Hamada M, Okayama H, Hara Y, Hayashi Y, Kodama $\mathrm{K}$, et al. Left ventricular hypertrophy precedes other target-organ damage in primary aldosteronism. Hypertension. 1997;29:723-7.

61. Goldkorn R, Yurenev A, Blumenfeld J, Fishman D, Devereux RB. Echocardiographic comparison of left ventricular structure and function in hypertensive patients with primary aldosteronism and essential hypertension. Am J hypertension. 2002;15:340-5. 
62. Catena C, Colussi G, Lapenna R, Nadalini E, Chiuch A, Gianfagna $\mathrm{P}$, et al. Long-term cardiac effects of adrenalectomy or mineralocorticoid antagonists in patients with primary aldosteronism. Hypertension. 2007;50:911-8.

63. Morillas P, Castillo J, Quiles J, Nunez D, Guillen S, BertomeuGonzalez V, et al. [Prevalence of primary aldosteronism in hypertensive patients and its effect on the heart]. Rev Esp Cardiol. 2008;61:418-21.

64. Muiesan ML, Salvetti M, Paini A, Agabiti-Rosei C, Monteduro $\mathrm{C}$, Galbassini $\mathrm{G}$, et al. Inappropriate left ventricular mass in patients with primary aldosteronism. Hypertension. 2008;52: 529-34.

65. Iacobellis G, Petramala L, Cotesta D, Pergolini M, Zinnamosca $\mathrm{L}$, Cianci $\mathrm{R}$, et al. Adipokines and cardiometabolic profile in primary hyperaldosteronism. J Clin Endocrinol Metab. 2010;95: 2391-8.

66. Lin YH, Huang KH, Lee JK, Wang SM, Yen RF, Wu VC, et al. Factors influencing left ventricular mass regression in patients with primary aldosteronism post adrenalectomy. J Renin Angiotensin Aldosterone Syst. 2011;12:48-53.

67. Lin YH, Lee HH, Liu KL, Lee JK, Shih SR, Chueh SC, et al. Reversal of myocardial fibrosis in patients with unilateral hyperaldosteronism receiving adrenalectomy. Surgery. 2011;150: 526-33.

68. Lin YH, Wang SM, Wu VC, Lee JK, Kuo CC, Yen RF, et al. The association of serum potassium level with left ventricular mass in patients with primary aldosteronism. Eur J Clin Investig. 2011;41:743-50.

69. Pimenta E, Gordon RD, Ahmed AH, Cowley D, Leano R, Marwick TH, et al. Cardiac dimensions are largely determined by dietary salt in patients with primary aldosteronism: results of a case-control study. J Clin Endocrinol Metab. 2011;96:2813-20.

70. Curione M, Petramala L, Savoriti C, Verrenti M, Baiocco E, Salvatore S, et al. Electrical and Myocardial Remodeling in Primary Aldosteronism. Front Cardiovasc Med. 2014;1:7.

71. Cesari M, Letizia C, Angeli P, Sciomer S, Rosi S, Rossi GP. Cardiac remodeling in patients with primary and secondary aldosteronism: a tissue doppler study. Circ Cardiovasc Imaging. 2016;9:e004815.

72. Yang Y, Zhu LM, Xu JZ, Tang XF, Gao PJ. Comparison of left ventricular structure and function in primary aldosteronism and essential hypertension by echocardiography. Hypertens Res. 2017;40:243-50.

73. Lin YH, Wu XM, Lee HH, Lee JK, Liu YC, Chang HW, et al. Adrenalectomy reverses myocardial fibrosis in patients with primary aldosteronism. J Hypertens. 2012;30:1606-13.

74. Liao MT, Wu XM, Chang CC, Liao CW, Chen YH, Lu CC, et al. The Association between Glomerular Hyperfiltration and Left Ventricular Structure and Function in Patients with Primary Aldosteronism. Int J Med Sci. 2015;12:369-77.

75. Hung CS, Ho YL, Chang YY, Wu VC, Wu XM, Lee JK, et al. Twenty-four-hour urinary aldosterone predicts inappropriate left ventricular mass index in patients with primary aldosteronism. ScientificWorldJournal. 2013;2013:294594.

76. Frustaci A, Letizia C, Verardo R, Grande C, Francone M, Sansone L, et al. Primary aldosteronism-associated cardiomyopathy: Clinical-pathologic impact of aldosterone normalization. Int $\mathbf{J}$ Cardiol. 2019;292:141-7.

77. Rossi GP, Di Bello V, Ganzaroli C, Sacchetto A, Cesari M, Bertini A, et al. Excess aldosterone is associated with alterations of myocardial texture in primary aldosteronism. Hypertension. 2002;40:23-7.

78. Galetta F, Bernini G, Franzoni F, Bacca A, Fivizzani I, Tocchini $\mathrm{L}$, et al. Cardiac remodeling in patients with primary aldosteronism. J Endocrinol Investig. 2009;32:739-45.
79. Freel EM, Mark PB, Weir RA, McQuarrie EP, Allan K, Dargie $\mathrm{HJ}$, et al. Demonstration of blood pressure-independent noninfarct myocardial fibrosis in primary aldosteronism: a cardiac magnetic resonance imaging study. Circ Cardiovasc Imaging. 2012;5:740-7.

80. Su MY, Wu VC, Yu HY, Lin YH, Kuo CC, Liu KL, et al. Contrast-enhanced MRI index of diffuse myocardial fibrosis is increased in primary aldosteronism. J Magn Reson Imaging. 2012;35:1349-55.

81. Lee HH, Hung CS, Wu XM, Wu VC, Liu KL, Wang SM, et al. Myocardial ultrasound tissue characterization of patients with primary aldosteronism. Ultrasound Med Biol. 2013;39:54-61.

82. Grytaas MA, Sellevag K, Thordarson HB, Husebye ES, Lovas $\mathrm{K}$, Larsen TH. Cardiac magnetic resonance imaging of myocardial mass and fibrosis in primary aldosteronism. Endocr Connect. 2018;7:413-24.

83. Lin YH, Shiau YC, Yen RF, Lin LC, Wu CC, Ho YL, et al. The relation between myocardial cyclic variation of integrated backscatter and serum concentrations of procollagen propeptides in hypertensive patients. Ultrasound Med Biol. 2004;30:885-91.

84. Hung CS, Chou CH, Wu XM, Chang YY, Wu VC, Chen YH, et al. Circulating tissue inhibitor of matrix metalloproteinase- 1 is associated with aldosterone-induced diastolic dysfunction. J Hypertens. 2015;33:1922-30.

85. Hattori T, Murase T, Sugiura Y, Nagasawa K, Takahashi K, Ohtake M, et al. Effects of salt status and blockade of mineralocorticoid receptors on aldosterone-induced cardiac injury. Hypertens Res. 2014;37:125-33.

86. Habibi J, DeMarco VG, Ma L, Pulakat L, Rainey WE, WhaleyConnell AT, et al. Mineralocorticoid receptor blockade improves diastolic function independent of blood pressure reduction in a transgenic model of RAAS overexpression. Am J Physiol Heart Circ Physiol. 2011;300:H1484-91.

87. Stoddard MF, Pearson AC, Kern MJ, Ratcliff J, Mrosek DG, Labovitz AJ. Influence of alteration in preload on the pattern of left ventricular diastolic filling as assessed by Doppler echocardiography in humans. Circulation. 1989;79:1226-36.

88. Nagueh SF, Appleton CP, Gillebert TC, Marino PN, Oh JK, Smiseth OA, et al. Recommendations for the evaluation of left ventricular diastolic function by echocardiography. Eur J Echocardiogr. 2009;10:165-93.

89. Paulus WJ, Tschope C, Sanderson JE, Rusconi C, Flachskampf FA, Rademakers FE, et al. How to diagnose diastolic heart failure: a consensus statement on the diagnosis of heart failure with normal left ventricular ejection fraction by the Heart Failure and Echocardiography Associations of the European Society of Cardiology. Eur heart J. 2007;28:2539-50.

90. Ommen SR, Nishimura RA, Appleton CP, Miller FA, Oh JK, Redfield MM, et al. Clinical utility of Doppler echocardiography and tissue Doppler imaging in the estimation of left ventricular filling pressures: a comparative simultaneous Dopplercatheterization study. Circulation. 2000;102:1788-94.

91. Liao CW, Chen A, Lin YT, Chang YY, Wang SM, Wu VC, et al. The Relation Between the Degree of Left Ventricular Mass Regression and Serum Potassium Level Change in Patients With Primary Aldosteronism After Adrenalectomy. J Investig Med. 2015;63:816-20.

92. Galderisi M, Petrocelli A, Alfieri A, Garofalo M, de Divitiis O. Impact of ambulatory blood pressure on left ventricular diastolic dysfunction in uncomplicated arterial systemic hypertension. Am J Cardiol. 1996;77:597-601.

93. Chang YY, Liao CW, Tsai CH, Chen CW, Pan CT, Chen ZW, et al. Left ventricular dysfunction in patients with primary aldosteronism: a propensity score-matching follow-up study with tissue doppler imaging. J Am Heart Assoc. 2019;8:e13263. 
94. Tseng WY, Liao TY, Wang JL. Normal systolic and diastolic functions of the left ventricle and left atrium by cine magnetic resonance imaging. J Cardiovasc Magn Reson. 2002;4:443-57.

95. Indra T, Holaj R, Strauch B, Rosa J, Petrak O, Somloova Z, et al. Long-term effects of adrenalectomy or spironolactone on blood pressure control and regression of left ventricle hypertrophy in patients with primary aldosteronism. J Renin Angiotensin Aldosterone Syst. 2015;16:1109-17.

96. Yoshitomi Y, Nishikimi T, Abe H, Yoshiwara F, Suzuki T, Ashizawa A, et al. Comparison of changes in cardiac structure after treatment in secondary hypertension. Hypertension. 1996;27:319-23.

97. Rossi GP, Cesari M, Cuspidi C, Maiolino G, Cicala MV, Bisogni $\mathrm{V}$, et al. Long-term control of arterial hypertension and regression of left ventricular hypertrophy with treatment of primary aldosteronism. Hypertension (Dallas, Tex: 1979). 2013;62:62-9.

98. Arabidze GG, Chikhladze NM, Sergakova LM, Iarovaia EB. [Left ventricular myocardial structure and function in patients with primary aldosteronism]. Ter Arkh. 1999;71:13-9.

99. Rossi GP, Sacchetto A, Pavan E, Scognamiglio R, Pietra M, Pessina AC. Left ventricular systolic function in primary aldosteronism and hypertension. J Hypertens. 1998;16:2075-7.

100. Liao M-T, Wu X-M, Chang C-C, Liao C-W, Chen Y-H, Lu C-C, et al. The Association between Glomerular Hyperfiltration and Left Ventricular Structure and Function in Patients with Primary Aldosteronism. Int J Med Sci. 2015;12:369-77.

101. Hung C-S, Wu X-M, Chen C-W, Chen Y-H, Wu V-C, Liao $\mathrm{C}-\mathrm{W}$, et al. The relationship among cardiac structure, dietary salt and aldosterone in patients with primary aldosteronism. Oncotarget. 2017;8:73187-97.

102. Gaddam K, Corros C, Pimenta E, Ahmed M, Denney T, Aban I, et al. Rapid Reversal of Left Ventricular Hypertrophy and Intracardiac Volume Overload in Patients With Resistant Hypertension and Hyperaldosteronism. Hypertension (Dallas, Tex: 1979). 2010;55:1137-42.

103. Pellerin D, Sharma R, Elliott P, Veyrat C. Tissue Doppler, strain, and strain rate echocardiography for the assessment of left and right systolic ventricular function. Heart (Br Card Soc). 2003;89: iii9-17.

104. Choi EY, Ha JW, Yoon SJ, Shim CY, Seo HS, Park S, et al. Increased plasma aldosterone-to-renin ratio is associated with impaired left ventricular longitudinal functional reserve in patients with uncomplicated hypertension. J Am Soc Echocardiogr: Off Publ Am Soc Echocardiogr. 2008;21:251-6.

105. Hidaka T, Shiwa T, Fujii Y, Nishioka K, Utsunomiya H, Ishibashi $\mathrm{K}$, et al. Impact of aldosterone-producing adenoma on cardiac structures in echocardiography. $\mathrm{J}$ Echocardiogr. 2013;11:123-9.

106. Krzesinski P, Uzieblo-Zyczkowska B, Gielerak G, Stanczyk A, Kurpaska M, Piotrowicz K. Global longitudinal two-dimensional systolic strain is associated with hemodynamic alterations in arterial hypertension. J Am Soc Hypertens. 2015;9:680-9.

107. Mayet J, Ariff B, Wasan B, Chapman N, Shahi M, Senior R, et al. Midwall myocardial shortening in athletic left ventricular hypertrophy. Int J Cardiol. 2002;86:233-8.

108. Sitia S, Tomasoni L, Turiel M. Speckle tracking echocardiography: a new approach to myocardial function. World J Cardiol. 2010;2:1-5.

109. Kouzu H, Yuda S, Muranaka A, Doi T, Yamamoto H, Shimoshige $\mathrm{S}$, et al. Left ventricular hypertrophy causes different changes in longitudinal, radial, and circumferential mechanics in patients with hypertension: a two-dimensional speckle tracking study. J Am Soc Echocardiogr: Off Publ Am Soc Echocardiogr. 2011;24:192-9.

110. Boulestreau R, Cremer A, Delarche N, Gosse P. [Alteration of left ventricular longitudinal systolic function in $2 \mathrm{D}$-strain in primary aldosteronism: A new target organ damage marker]. Annales de Cardiologie et d'angeiologie. 2018;67:315-20.

111. Wang D, Xu JZ, Chen X, Chen Y, Shao S, Zhang W, et al. Speckle-Tracking Echocardiographic Layer-Specific Strain Analysis on Subclinical Left Ventricular Dysfunction in Patients With Primary Aldosteronism. Am J Hypertens. 2019;32:155-62.

112. Catena C, Colussi GL, Marzano L, Sechi LA. Predictive factors of left ventricular mass changes after treatment of primary aldosteronism. Horm Metab Res. 2012;44:188-93.

113. Wu VC, Yang SY, Lin JW, Cheng BW, Kuo CC, Tsai CT, et al. Kidney impairment in primary aldosteronism. Clin Chim Acta. 2011;412:1319-25.

114. Borlaug BA, Paulus WJ. Heart failure with preserved ejection fraction: pathophysiology, diagnosis, and treatment. Eur heart J. 2011;32:670-9.

115. Katz AM, Rolett EL. Heart failure: when form fails to follow function. Eur heart J. 2016;37:449-54.

116. Hoit BD. Left atrial size and function: role in prognosis. J Am Coll Cardiol. 2014;63:493-505.

117. Reil JC, Hohl M, Selejan S, Lipp P, Drautz F, Kazakow A, et al. Aldosterone promotes atrial fibrillation. Eur heart J. 2012;33:2098-108.

118. Wang D, Xu JZ, Chen X, Xu TY, Zhang W, Li Y, et al. Left atrial myocardial dysfunction in patients with primary aldosteronism as assessed by speckle-tracking echocardiography. J Hypertens. 2019;37:2032-40.

119. Monticone S, Burrello J, Tizzani D, Bertello C, Viola A, Buffolo F, et al. Prevalence and Clinical Manifestations of Primary Aldosteronism Encountered in Primary Care Practice. J Am Coll Cardiol. 2017;69:1811-20.

120. Huang WC, Chen YY, Lin YH, Chen L, Lin PC, Lin YF, et al. Incidental Congestive Heart Failure in Patients With Aldosterone-Producing Adenomas. J Am Heart Assoc. 2019;8: e012410.

121. Verdecchia P, Carini G, Circo A, Dovellini E, Giovannini E, Lombardo $\mathrm{M}$, et al. Left ventricular mass and cardiovascular morbidity in essential hypertension: the MAVI study. J Am Coll Cardiol. 2001;38:1829-35.

122. Nadruz W. Myocardial remodeling in hypertension. J Hum Hypertens. 2015;29:1-6.

123. Verdecchia P, Angeli F, Achilli P, Castellani C, Broccatelli A, Gattobigio R, et al. Echocardiographic left ventricular hypertrophy in hypertension: marker for future events or mediator of events? Curr Opin Cardiol. 2007;22:329-34.

124. Chen ZW, Tsai CH, Pan CT, Chou CH, Liao CW, Hung CS, et al. Endothelial Dysfunction in Primary Aldosteronism. Int J Mol Sci. 2019;20:5214.

125. Murata M, Kitamura T, Tamada D, Mukai K, Kurebayashi S, Yamamoto T, et al. Plasma aldosterone level within the normal range is less associated with cardiovascular and cerebrovascular risk in primary aldosteronism. J Hypertens. 2017;35:1079-85.

126. Ohno Y, Sone M, Inagaki N, Yamasaki T, Ogawa O, Takeda Y, et al. Prevalence of cardiovascular disease and its risk factors in primary aldosteronism: a multicenter study in Japan. Hypertension (Dallas, Tex: 1979). 2018;71:530-7.

127. Chang YH, Chung SD, Wu CH, Chueh JS, Chen L, Lin PC. et al. Surgery decreases the long-term incident stroke risk in patients with primary aldosteronism. Surgery. 2020;167:367-77.

128. Hundemer GL, Curhan GC, Yozamp N, Wang M, Vaidya A. Cardiometabolic outcomes and mortality in medically treated primary aldosteronism: a retrospective cohort study. Lancet Diabetes Endocrinol. 2018;6:51-59.

129. Hundemer GL, Curhan GC, Yozamp N, Wang M, Vaidya A. Incidence of Atrial Fibrillation and Mineralocorticoid Receptor Activity in Patients With Medically and Surgically Treated Primary Aldosteronism. JAMA Cardiol. 2018;3:768-74. 
130. Tsioufis C, Tsiachris D, Dimitriadis K, Stougiannos P, Missovoulos $\mathrm{P}$, Kakkavas A, et al. Myocardial and aortic stiffening in the early course of primary aldosteronism. Clin Cardiol. 2008;31:431-6.

131. Bernini G, Bacca A, Carli V, Carrara D, Materazzi G, Berti P, et al. Cardiovascular changes in patients with primary aldosteronism after surgical or medical treatment. J Endocrinol Investig. 2012;35:274-80.

132. Tarazi RC, Ibrahim MM, Bravo EL, Dustan HP. Hemodynamic Characteristics of Primary Aldosteronism. N Engl J Med. 1973;289:1330-5.
133. Lin YH, Huang KH, Lee JK, Wang SM, Yen RF, Wu VC, et al. Factors influencing left ventricular mass regression in patients with primary aldosteronism post adrenalectomy. J ReninAngiotensin-Aldosterone Syst. 2011;12:48-53.

134. Liao CW, Chen A, Lin YT, Chang YY, Wang SM, Wu VC, et al. The relation between the degree of left ventricular mass regression and serum potassium level change in patients with primary aldosteronism after adrenalectomy. J Investig Med: Off Publ Am Fed Clin Res. 2015;63:816-20. 